\title{
O TRIUNFO DA ESCOLÁSTICA, A GLÓRIA DA EDUCAÇÃO
}

\author{
Mitton José de AlmeidA
}

RESUMO: Estudo sobre um afresco do século XIV e a memória e persistência da Escolástica na educação contemporânea.

Palavras-chave: Escolástica. Currículo. Educação. "Arte da memória".

THE TRIUMPH OF THE SCHOLASTIC, THE GLORY OF EDUCATION

ABSTRACT: A study of a fresco of the $14^{\text {th }}$ century and the memory and persistence of the scholasticism in contemporary education.

Key words: Scholastic. Curriculum. Education. "Art of memory".

* Professor livre-docente da Faculdade de Educação da Universidade Estadual de Campinas (UNICAMP).E-mail:mja@directnet.com.br

Educ. Soc., Campinas, vol. 26, n. 90, p. 17-39, Jan./Abr. 2005

Disponível em <http://www.cedes.unicamp.br> 
7 ndrea Bonaiuti (1343-1377) pintou entre 1366 e 1368 na casa do capítulo dominicano, em Florença, construção pertencente à igreja de Santa Maria Novella, em afresco, uma alegoria d' $O$ Triunfo de S. Tomás, homenagem à glória terrena e celeste do santo, que nasceu em 1225 e morreu em 1274.

O local originalmente construído tinha uma dupla função: a de capela funerária do rico mercador florentino Buonamico Guidalotti, que deixou em testamento uma grande soma de dinheiro para os dominicanos, para "ornamentar e pintar" a capela - o túmulo de Guidalotti e de sua mulher estão em frente do altar -; e de casa do capítulo dominicano, um colegiado tradicionalmente devotado ao conhecimento. Desde 1311 eles já tinham um studium, na região do priorado de Santa Maria Novella.

O programa visual exposto nas quatro paredes laterais da capela do capítulo é composto de quatro grandes afrescos que, subindo em forma ogival, encontram-se no centro da abóbada.

O afresco que vamos interpretar, uma "celebração da aprendizagem”, pintado para uma audiência especializada, é um retrato do conhecimento e expressa visualmente o conjunto complexo do conhecimento escolástico sistemático, ou como já disseram, sistematizado.

Suas imagens são um conjunto ordenado de personificações das artes liberais, dos ilustres praticantes dos diversos tipos de conhecimento, além das sete virtudes, dos sete planetas e dos sete dons do Espírito Santo.

Sobre o altar, vemos um afresco que parte do caminho do calvário, para a crucificação e a descida ao limbo, e, na volta acima, estão a ressurreição e a ascensão.

Uma das cenas importantes, que demonstra a vocação histórica dos dominicanos para o conhecimento, está na volta do teto: a cena do pentecostes, quando os apóstolos recebem o Espírito Santo, e passam a ser capazes de disseminar a mensagem bíblica nas diferentes línguas.

Os outros afrescos representam as atividades principais da ordem dos dominicanos, os principais santos dominicanos, e a glorificação da ordem, além de diversos episódios de São Pedro Mártir, importante santo dominicano de devoção florentina, e também na volta do teto há uma nave, que representa tradicionalmente a nave da Igreja, a navicela. 
O afresco do triunfo de Tomás de Aquino traz a representação visual da natureza, da aquisição e da disseminação do conhecimento.

Tributárias dessa alegoria, todas as imagens participam como um coro visual em torno da imagem central de Aquino sentado no trono. São imagens agentes que, ao exporem seus sentidos específicos, compõem ao mesmo tempo o significado total do afresco. Circundam o santo, num movimento de descenso e ascensão, e carreiam para a imagem central seus significados, rigidamente ordenados, seriados e classificados. Apesar dessa estrutura geométrica estática, na qual cada imagem se define por si, seus significados vazam e participam da retórica visual da composição da imagem de Aquino, em posição central e superior.

Abaixo do círculo intermediário, dos planetas, no universo aquiniano, aristotélico, a Terra ocupa a posição mais inferior, a esfera sublunar, correspondente à sua inferioridade, pois é o lugar da geração e da corrupção, da impermanência, da instabilidade. O lugar onde se faz necessária a ação do homem juntamente com a divina para a correção da obra de Deus.

Assim, vemos em movimento visual a atuação de Aquino como educador e condutor de almas através dos três círculos. Santo e patrono das escolas católicas e da educação, a partir de 1567, foi elevado à categoria de doutor da Igreja, e chamado de "doutor angélico", em alusão à sua sabedoria e aos anjos que habitam o primeiro círculo, o mais elevado, o mais próximo de Deus, o círculo das inteligências angélicas, do intelecto.

\section{Primeira aproximação}

No plano superior, pintado em proporções maiores que as de outras figuras, segundo a tradicional representação do sábio e da tradição visual da representação da glória de Cristo, Tomás de Aquino está sentado num trono requintado, tendo mais acima pintada, dentro de uma moldura redonda, uma figura de mulher em meio corpo, que representa a sabedoria.

Aquino abre um livro, a Bíblia, em Sabedoria, VII, 7: "Por isso supliquei, e inteligência me foi dada; invoquei, e o espírito da Sabedoria veio a mim". Essas palavras ainda são recitadas na abertura da missa em homenagem ao santo, em seu dia comemorativo, 7 de março. 
Acima do trono, como que presidindo toda a alegoria pedagógica do afresco, pintadas à maneira de celestiais, estão as sete virtudes. Entre elas, reinam, mais acima, as três virtudes teologais.

Em cada lado do santo, em posições equivalentes, estão profetas do Velho Testamento, com São Paulo, e os quatro evangelistas. Com exceção de David, que segura o seu atributo, a harpa, todos os outros seguram livros, fechados ou abertos, onde se podem ler textos.

Aos pés de Aquino, subjugados e humilhados, estão três escritores cujos textos foram explicitamente rejeitados pela Igreja: Ario (c. 260-330), cristão cuja visão antitrinitária foi rejeitada pela Igreja e condenado como herege; Averroés (1126-98), muçulmano, que escreveu muitos comentários sobre Aristóteles, cuja visão da unidade do intelecto humano e a conseqüente não-necessidade de imortalidade pessoal foi discordada e exaustivamente discutida por Aquino; e Sabelio (séc III), acusado de heresia por causa de sua visão sobre a Trindade.

Já em 367 d.C., Atanásio, um dos "pais da Igreja”, escreveu a Epístola 39, na qual condena diversos textos de grupos cristãos, principalmente gnósticos que divergiam da nova direção e poder que a Igreja vinha assumindo, tornando-se romana, modelando-se como o Império, a partir de Constantino. Escreve Atanásio:

[Alguns hereges gnósticos] escreveram livros que chamam livros de mesa, que marcaram com estrelas, às quais deram os nomes dos Santos. Esses que escreveram tais livros em meio à verdade atraíram sobre si uma reprovação dupla, porque se esmeraram numa ciência mentirosa e desprezível e desviaram, com idéias maldosas, os ignorantes e os simples, da fé correta e estabelecida na verdade íntegra, sob a presença de Deus.

Já que os citamos como heréticos e assassinos, sendo nós os possuidores das Divinas Escrituras para a salvação, e já que temos, como Paulo escreveu aos Coríntios, que algumas poucas pessoas simples podem ser desviadas da simplicidade e pureza, pela astúcia de certas pessoas, e podem, no futuro, ler outros livros que são chamados apócrifos, iludidos pela semelhança de seus nomes com os dos livros verdadeiros, venho pedir-lhes que tenham paciência se eu também vos escrevo com intuito de lembrar-lhes assuntos com os quais estais familiarizados, levado pela necessidade e para o bem da Igreja.

Mais abaixo, num friso estão escritos, à esquerda, os sete dons do Espírito Santo, e à direita, o conjunto das sete disciplinas funda- 
mentais, o Quadrivium e o Trivium. Abaixo destes, os sete planetas, como vistos na época: Sol, Marte, Saturno, Júpiter, Mercúrio, Vênus e a Lua.

A metade inferior do afresco apresenta uma seqüência de bancos enfileirados ao estilo similar dos bancos entalhados de coro. Neles, sentam-se 14 figuras femininas, como virtudes: à esquerda, personificam o direito civil e canônico e os diversos ramos da teologia; à direita, as disciplinas fundamentais, aritmética, geometria, astronomia, música, dialética, retórica, gramática.

Abaixo delas, estão as figuras masculinas que representam os diferentes ramos do conhecimento: o primeiro setenário das ciências teologais: Justiniano, o direito civil; Clemente $\mathrm{V}$ ou Inocêncio IV, o direito canônico; Platão, a teologia antiga, e São Jerônimo, São Dionísio, o Areopagita, São João Damasceno, Santo Agostinho, as quatro ciências teologais. No segundo setenário, o das artes liberais, vemos: Pitágoras, a aritmética; Euclides, a geometria; Ptolomeu, a astronomia; Tubalcain, música; Aristóteles, dialética; Cícero, retórica; e Donato, gramática.

Há outras inúmeras inscriçôes, agora muito apagadas, com finalidades didáticas, tendo como movimento condutor a glorificação de São Tomás de Aquino, como teólogo e professor, o que demonstra, visualmente, seus escritos como divinamente inspirados, e superior a todos os autores não-cristãos.

Evidentemente, tanto os comitentes quanto os criadores do programa visual eram pessoas muito cultas e envolvidas no complexo sistema de conhecimento desse programa visual de educação da alma, representativo do movimento em imagens e textos da arte da memória. Suas mensagens educavam e inspiravam, principalmente, os dominicanos da igreja de Santa Maria Novella, envolvidos no ensino, tanto escrito quanto oral, cujos estatutos estipulavam que o currículo do studium deveria ser elaborado com base nas obras de Aquino.

E também todos que ali freqüentassem recebiam essas lições como reflexões sobre suas palavras e açôes, quando ocorriam ali as assembléias comunais em certas datas do ano litúrgico. E também os membros da ordem quando, nesse local, confessavam suas faltas ao prior.

Essa educação visual da memória também envolvia em sua pedagogia a comunidade dominicana de Santa Maria Novella, que nesse local realizava seus ofícios religiosos, discutia assuntos administra- 
tivos, fazia a eleição do prior e recebia visitantes importantes, além de promover diversas reuniōes regionais e gerais da ordem. Enfim, um local fantástico feito de imagens e textos para educação e aprendizado, muito freqüentado, tanto por religiosos como por leigos.

\section{Segunda aproximação}

A luz física é um reflexo da luz eterna, da mesma forma que a sabedoria humana é um reflexo da sabedoria divina. E assim são os atributos de Aquino, doutor divino, cujos escritos ali são celebrados visualmente como divinamente inspirados.

Estamos vendo também um afresco, como quase todo afresco religioso, com finalidades didáticas, uma exposição, ao mesmo tempo um ensinamento conduzido pela pedagogia escolástica. A Suma teológica de Tomás de Aquino, poderíamos dizer, é o seu manual.

Esse afresco é uma visão em imagens coerente com o esquema do que é o conhecimento para a comunidade dominicana de Santa Maria Novella, em Florença, e para a ordem dominicana em geral. Ensina com suas imagens e inúmeros escritos que, divinamente inspirado, o conhecimento de Aquino foi-lhe dado por Deus, estruturado sobre a autoridade e o legado da filosofia antiga.

As imagens mostram os sábios, profetas, filósofos que devem ser seguidos, e quais ciências, disciplinas, práticas são adequadas para esse caminho de sabedoria. Estabelece, ao mesmo tempo, visualmente, a hierarquia entre todas essas figuras, uma escala que parte dos graus mais inferiores, portanto em maior número, e sobe em direção ao intelecto divino, sede dos fundamentos, próximo do fundamento dos fundamentos, o "uno". Essa escala é estruturada em graus seriados de abstrações sucessivas, representada no afresco por alegorias visuais.

Para Aquino, basta olharmos a criação para vermos que Deus existe e que o mundo e o homem são imagens de Deus. Porque, ao observarmos o mundo, vemos todos os tipos de efeitos para os quais devemos supor que haja uma causa. E essa causa supõe, necessariamente, uma "causa primeira”, começo e fim de todo o movimento. É um universo finito, limitado e ordenado pela "causa primeira", pois sua ausência levaria a uma proliferação infinita de causas, à desordem, ao caos. 
Desordem e caos que foram sempre atribuídos ao pensamento divergente, aos grupos contrários à orientação escolástica, aos textos que não seguiam as formas estabelecidas de exposição e argumentação, e não afirmavam e confirmavam a verdade única e universal, isto é, católica.

Acima de Aquino, em grau mais alto, presidindo visualmente as figuras que lhe estão abaixo, inclusive o próprio santo, vemos as três virtudes teologais, a Fé, a Esperança e a Caridade, princípios e fins de toda a sabedoria que permite ao homem honrar o Criador.

Escreve o doutor divino, na Suma teológica, na $1^{\text {a }}$ Parte da $2^{\text {a }}$ Parte, Questôes 62, 63 e 65:

As virtudes aperfeiçoam o homem aos atos pelos quais ele se ordena à felicidade (...) Há, porém, uma dupla felicidade ou fim último para o homem. (...) A primeira é proporcionada à natureza humana, à qual o homem pode chegar pelos princípios de sua natureza. A outra é a felicidade ou a bemaventurança que excede a natureza do homem, à qual o homem pode chegar somente pela virtude divina (...). (...) é necessário que sejam divinamente sobreacrescentados ao homem alguns princípios pelos quais ele se ordene de tal modo à felicidade sobrenatural assim como pelos princípios naturais ele se ordena ao fim que lhe é conatural, embora mesmo isto não seja possível sem o auxílio divino. Tais princípios são chamados virtudes teologais, seja porque têm a Deus por objeto, na medida em que por eles nos ordenamos corretamente a Deus, seja porque são infundidos em nós somente por Deus, seja porque estas virtudes nos são conhecidas apenas pela divina revelação nas Sagradas Escrituras.

Em plano inferior, ladeiam Aquino, as virtudes intelectuais e morais, as virtudes cardinais herdadas dos romanos: a Prudência, a Justiça, a Fortaleza, a Temperança.

Ora, o objeto das virtudes teologais é o próprio Deus, que é o fim último de todas as coisas, na medida em que excede o conhecimento de nosso entendimento. Já o objeto das virtudes intelectuais e morais é algo que pode ser alcançado pela inteligência humana.

As três virtudes teologais e as quatro cardinais fecham o primeiro setenário, e emanam seus significados virtuosos para outros setenários que demonstram visualmente a virtude composta da sabedoria nessa escala do conhecimento, uma espécie de currículo, disciplinas a serem percorridas por aquele que almejasse tal virtude. Cada disciplina é uma 
virtude em si, para ser estudada e praticada, e, ao mesmo tempo, participante necessária e pré-requisito para todas as demais.

O setenário das artes liberais, por exemplo, tal como as sete virtudes, expõe-se como uma lição visual sobre o significado e a mística dos números. Compóe-se, por exemplo, de uma tríade relativa às esferas espirituais e mentais superiores do intelecto - a gramática, a dialética, e a retórica, que compõem o Trivium - e por meio da perfeição do número três, número celeste, da Trindade, relaciona-se às três virtudes teologais. Assim o Trivium, conjunto de disciplinas que se ocupam do discurso e da palavra, sintoniza-se com as virtudes mais próximas da inteligência divina.

Em contraposição e complemento ao trio das virtudes espirituais, soma-se o quatro, número terrestre, corpóreo - terra, ar, fogo, água - relacionado ao quadrado, à cruz: o Quadrivium, e suas disciplinas dedicadas aos estudos da natureza - aritmética, geometria, música, astronomia - e ao conhecimento simbólico dos números e seus suportes corpóreos - a física, os sons, os planetas.

Ao lado de Aquino, sentam-se também os profetas do Velho Testamento, mais Paulo e os quatro evangelistas.

Cada uma, e todas em seu harmonioso conjunto, as figuras do afresco representam a sabedoria, e remetem a vidas, idéias, práticas, escritos, que devem ser estudados como fundamentos imprescindíveis para a formação do mestre cristão, que tendo aprendido a discriminar, classificar, ordenar o bom conhecimento, que é também o conhecimento do bem, pode honrar a Deus e à Ciência, ao mesmo tempo.

Essa pedagogia visual, poderoso instrumento de educação para os freqüentadores da casa do capítulo dominicana, tem como estrutura condutora a "arte da memória", sobre a qual o mesmo Aquino já havia atentado em seu texto sobre a obra De memoria et reminiscentia, na qual Aristóteles escreve sobre a precedência absoluta da imagem com relação à fala, e sobre a essência imagética do intelecto, e por isso o único que poderia entender uma gramática imaginal. Aquino comenta que, graças às qualidades intrínsecas da imagem, aquilo que é visto é mais fácil de lembrar, e que conceitos abstratos ou frases, mais difíceis de lembrar, necessitam, para tanto, de um suporte imagético. Ramon Lullo, praticante e teórico da "arte da memória", também já havia chamado a atenção para o fato de que "tudo o que é aceito, é aceito ao modo do recebedor". A 
imagem é recebida no espelho do espírito, e a alma pode aprender sobre o mundo que a circunda se este for traduzido na linguagem das imagens. $\mathrm{O}$ conhecimento claro é a translação de verdades reais em linguagem imaginal, verdades essas que estão gravadas na alma. Assim, a razão discursiva pode captá-las e fazer uso delas, servindo-se da "arte da memória”.

\section{Terceira aproximação}

Tomás de Aquino escreveu no De magistro:

Deve-se dizer que as coisas sobre as quais somos ensinados por meio da linguagem, sob um certo aspecto as conhecemos, e sob outro, as ignoramos. Se, por exemplo, nos querem ensinar o que é o homem, é necessário que já saibamos alguma coisa sobre ele, isto é, que tenhamos o conceito de animal ou de substância, ou ao menos o de ente, que não pode ser-nos desconhecido, e assim também, quando nos queiram explicar alguma conclusão, é necessário que já saibamos o que é sujeito e predicado, e que conheçamos também os princípios pelos quais a conclusão nos é ensinada, pois todo ensinamento procede de um conhecimento prévio.

A Suma teológica de Tomás de Aquino, texto de fins pedagógicos, um manual para as novas universidades, marca profundamente até hoje a concepção de conhecimento, e a pedagogia curricular de nossas universidades, principalmente o campo da educação, herdeira direta e persistente da educação cristã.

A Suma é perfeito exemplo do pensamento e da dialética escolásticos: não admite contradição, é um sistema de argumentação que parte de verdades indemonstráveis, princípios, e por intermédio de perguntas e respostas divide os argumentos por meio da distinção de oposiçôes, e, como conclusão, afirma uma unidade, uma resposta única e inequívoca.

Seguidores de Aquino, antigos escolásticos e neo-escolásticos contemporâneos, interessados somente por argumentos, são comentadores cujo pensamento se guia sempre por autoridades escritas e aceitas inquestionavelmente, e, modernamente, também por agrupamentos estatísticos. A experiência real serve somente para gerar exemplos para suas idéias e argumentos, e, como tal, é forçada a representar-se como casos particulares de princípios gerais, derivados de autores acadêmica e canonica- 
mente estabelecidos, equivalentes, no caso de religiosos, à palavra de Deus, no caso de acadêmicos, à palavra dos autores fundamentais.

Dessa maneira, nos textos de escolásticos predominam inúmeras citações de autores, a que chamam de autoridades, com os quais concordam ou discordam, seguindo sempre o mesmo método de argumentação, em busca da definição de verdades ou da verdade, a que hoje damos também o nome de objetividade, ou de ciência.

O raciocínio parte de questôes e argumentos possíveis e aceitos que tentam abarcar o assunto em questão. A argumentação parte de verdades supostas como irretocáveis, fundamentos aceitos sem discussão, pois são a origem de tudo, que evidentemente rejeitam o que não é concorde, e encaminham para uma conclusão, livre de contradições ou dúvidas, pois tudo seguiu uma demonstração lógica, causal, que é tomada como verdade.

Esse raciocínio faz com que a demonstração lógica apareça e pareça a demonstração da verdade, e essa é uma das principais falácias científicas predominantes hoje nas humanidades.

A demonstração lógica, os modelos de argumentação técnico-acadêmica baseados em determinados autores e teorias básicas, os fundamentos, ou os fundadores, substituem os conflitos, as dúvidas, o pensamento, a História. Mas estabelece para o fiel, o pesquisador, o professor, o aluno um aparato mental técnico, um ambiente de segurança e de certezas indubitáveis.

Para os escolásticos, o intelecto volta-se sempre aos primeiros princípios, os fundamentos, o que está logicamente anterior a qualquer coisa. Os particulares são interpretados e deduzidos por esse processo de raciocínio que parte e volta sempre aos primeiros princípios, confirmando-os e confinando-os numa espécie de tautologia científica. Uma espécie de máquina mental que produz pesquisas em série.

É um processo de raciocínio no qual predominam as diversas modalidades de silogismo e lógica, e não propriamente um processo de pensamento complexo, pluricausal, de concomitâncias, histórico. A causalidade predomina como fluxo ideológico orientador.

Dessa maneira, também o tempo, segue a linha causal-cronológica. O fim do raciocínio, principalmente quando se trata de particulares, não é o futuro, uma categoria temporal, mas, sim, uma categoria 
lógica, produzida por dedução. Da mesma forma, o princípio não é o passado, o tempo, a História, mas um ponto de início definido logicamente.

Para Aquino, o processo de conhecimento parte dos acidentes, e deve conduzir ao conhecimento da essência, da substância - a natureza fundamental de qualquer coisa, sua definição lógica estável, invariável, quaisquer que sejam as circunstâncias. Em nosso ambiente acadêmico, as essências são os fundamentos. Assim, da visão e investigação do mundo, somos conduzidos às essências do conhecimento, representadas pelos autores canônicos e fundamentais, pelos conceitos e pelas categorias abstratas, pelas formas perfeitas, imagem da luz pura. Uma espécie de "teologia da ciência", ou a epistemologia.

Escreve Aquino, na Suma teológica:

Chamamos sabedoria o conhecimento das realidades divinas e ciência o conhecimento das realidades humanas e criadas. O conhecimento de Deus a partir das criaturas pertence, por sua forma, à ordem da ciência; esta pertence à ordem da sabedoria por ser somente seu objeto. Quando julgamos as realidades criadas em função das realidades divinas, trata-se então mais de sabedoria que de ciência.

O raciocínio escolástico é uma forma de poder político, científico e retórico, que parte da demonstração lógica, racional, estabelece verdades, ou uma verdade que conduz e coage as opinióes dissidentes, o pensamento histórico e complexo.

É evidente a proximidade dessa maneira de produzir e fazer pesquisa e dos projetos nas instituições de pesquisa e ensino com o poder político mais amplo, partidário, e oficial. Não é necessário abrir muito os olhos para perceber a proporcionalidade que há entre os projetos e a quantidade de dinheiro necessária para sua execução. Quanto maior o financiamento, mais o projeto deverá realizar em forma e conteúdo a vontade do poder que o financia.

O modelo cristão-aquiniano, que já serviu à Igreja para que ela tivesse meios retóricos e teológicos para queimar hereges e heterodoxos, é o modelo predominante e o mais adequado para moldar a participação de educadores e pesquisadores no mundo oficial, e promovê-los a participantes legítimos das políticas públicas e científicas. Nunca os leigos têm estado tão ortodoxos e cristãos. 
No mundo neo-escolástico, os projetos são definidos não pelo tempo histórico, mas pelo tempo de sua aplicação. Portanto, mesmo que seu conteúdo seja "histórico", sua forma é lógico-causal, cronológica, a qual subordina os conteúdos dos projetos, igualando-os todos pelo formato oficial.

É essa mesma forma que permite o controle científico-político dos projetos: a avaliação. $\mathrm{O}$ controle, ou seja, a interrupção ou continuidade política dos projetos não está nas mãos dos pesquisadores, e sim dos técnicos da avaliação, que também são pesquisadores que atuam como pareceristas e avaliadores das instituiçõos de financiamento. A qualquer momento, por desobediência aos cânones, aos interesses pessoais, políticos, ou por qualquer razão, um projeto pode ser interrompido ou cancelado sem nenhuma responsabilidade maior com as pessoas envolvidas, que são imediatamente desligadas.

Para os escolásticos, o fim - nos projetos, ou nos planos, chamado de o objetivo - deve ser pensado e conduzido pelo intelecto, também chamado de "razão universal", instrumentado pelas faculdades de apreensão, e transformado em forma verbal lógica.

Esse movimento, segundo Aquino, é o seguinte: primeiro é pensado o fim, sempre um bem a ser alcançado, e deliberado por meio da definição da verdade. Em seguida, delibera-se sobre os meios, tendo em vista o fim, o objetivo, o bem, a verdade. Nesse momento, acontece a escolha dos meios para atingir o fim definido logicamente, portanto é o momento do controle das condiçóes circunstanciais, do desejo, dos apetites que podem desviar o ser envolvido da boa direção ao bem a ser alcançado.

O movimento, que se realiza por intermédio dos meios, deve encaminhar o projeto ao fim, ao bem a ser atingido, que se confunde com o início, o bem desejado. Como o objeto do fim, do objetivo, é sempre o bem, os meios serão controlados pelas virtudes. E a razão condutora é naturalmente sempre a razão do bem, o mal é "desrazão".

Escreve Aquino na Suma teológica que

pela inclinação natural o homem se ordena ao fim que lhe é conatural. Ora, isto se dá de duas maneiras. Primeiro, segundo a razão ou o intelecto, na medida em que este contém os primeiros princípios universais conhecidos para nós pela luz natural da inteligência, a partir dos quais procede a razão tanto 
na especulação quanto no agir. Em segundo, isto se dá pela retidão da vontade naturalmente tendente ao bem da razão.

Os erros e desvios serão atribuídos aos vícios, pois o mal, que segundo Aquino não é inerente ao homem, é um acidente, um desvio, é a ausência de bem que pode ser reposta, ou ensinada, ou verificada pelo projeto.

"O homem tem de bondade tanto quanto tem de Ser, e faltando-lhe plenitude de seu Ser, falta-lhe bondade, o que é chamado de mal", escreve Aquino, demonstrando que a razão sempre encaminha para o bem.

Argumentando logicamente, criando a sua "verdade" a partir de princípios não-demonstráveis, Aquino afirma que, ao observarmos a imperfeição existente no mundo, podemos ver que o mundo não criou a si próprio, pois nesse caso seria perfeito, mas foi criado por uma perfeição fora do mundo. $\mathrm{O}$ mundo foi criado pelo perfeito, em gradaçōes, ou degradações, que encontramos visivelmente na realidade ao observarmos a seqüência que dos seres menos animados, menos inteligentes e menos livres, como a matéria, vai ao ser mais animado, mais inteligente e mais livre, o homem.

E afirma que vemos isso tudo em ordem crescente, porque o mundo foi criado pelo "princípio primeiro", que o criou em ordem, do inferior ao superior. Não veríamos tal ordem crescente se tudo viesse da desordem, pois como a desordem poderia ter criado a ordem?

E tal ordem crescente, que permite ao escolástico e pesquisador definir seu ponto de partida seguro, deve estar necessariamente ligada a uma ordem finita e estável de causas. Aquino ensina que, se a regressão às causas não tivesse um ponto terminal, uma "causa primeira", as causas seriam causadas ao infinito, portanto seriam sem causa. Assim, o ponto terminal das séries regressivas causais tem seu fim na "causa primordial", Deus, ou os "fundamentos", ou os "princípios universais" de toda e qualquer ciência.

$\mathrm{Na}$ verdade, essa argumentação lógica, a partir de princípios indemonstráveis e causalidades, é uma política, uma hierarquia de poder, o poder dos "fundamentos indiscutíveis", ordenados, e a condenação de qualquer outra forma de conhecimento, da "desordem", da imperfeição, da dissidência. 
O pesquisador, de posse do bem, e tendo em vista que a vontade do homem sempre se encaminha para o bem, vai fazer com que o bem, o objetivo do projeto, realize-se, transforme o ser de cada um nele envolvido, tentando fazer com que o mal deixe de existir, pois é um desvio, não é inerente, pois nenhum ser, uma vez que é por definição bom, pode ser mau, "mas somente à medida que lhe falte Ser", como diz Aquino, pois o bem - o objetivo, a educação, o ensino, a pesquisa - e o ser - o pesquisador, o gestor, o aluno, o cientista - diferem somente em pensamento, mas são a mesma realidade, são conversíveis: o bem do projeto emana, logicamente, de e para o bom pesquisador, e legitima-o. Como legitima projetos que partem de um zero histórico, muitas vezes respaldados por pesquisas e diagnósticos preliminares do mal, e dirigem-se a bens ideais coletivos, como os que dizem basear-se nas necessidades das comunidades, da sociedade, da Nação.

Costumeiramente, as pesquisas e os diagnósticos desses projetos são orientados pela "virtude da estatística", tanto a matemática quanto aquela já introjetada no modo de pensar do pesquisador. A estatística, essa ciência política do lugar-comum, aliada à prática do poder discriminatório do bem e do mal da avaliação, desresponsabiliza o pesquisador, desvia-o da história humana e dá-lhe a ilusão de um ponto de vista neutro, de onde vê as aglomerações humanas agrupadas em categorias, como o próprio Deus pode, do alto, observar as suas criaturas.

A afirmada imparcialidade ou a neutralidade do pesquisador, ao contrário do que parece ser, é justamente a imersão completa no movimento cristão aquiniano, baseada que é na crença de um bem abstrato, como a ciência, ou no conhecimento intelectual de razões universais que pressupõem estruturas abstratas, conceitos, categorias neutras, isto é, isentas de mal, que não está nessas estruturas, mas que aparece naquelas da matéria das pessoas "reais", como erro, mau entendimento, ignorância, sujeiras que podem ser reveladas e depuradas pelo bem trazido pelo plano, projeto, pesquisa, pela educação, pela ciência. Esse formato abona o pesquisador, independentemente da sua alma pessoal.

Assim a educação e seus diferentes projetos atuam como a reposição lógica do bem, o preenchimento da falta de ser nos seus objetos: pessoas, instituiçóes ou políticas públicas. Como hoje percebemos, por exemplo, na ideologia da inclusão. 


\section{Comentário}

Quando há uma disputa por espaço e poder entre os diversos grupos em qualquer área educacional, podemos ver que todos têm um projeto com um objetivo, um fim, encaminhado ao bem. E as discussões tomam a forma das disputas religiosas, em que o bem proposto pelo grupo, ou intelectual, contrário é o mal que deve ser combatido. E não há outra maneira de acontecer, pois, para além das mesquinharias e competições, honestas ou não, a grande estrutura política que dá sentido à educação e à ciência, tanto nos currículos universitários, ainda e sempre escolásticos, com suas disciplinas fundamentais, seriação, pré-requisitos, quanto em sua pesquisa e organização docente e discente, é a do cristianismo escolástico e militante.

Uma estrutura que não provoca a mínima contradição com qualquer tipo de regime político e econômico, pois é uma estrutura de poder, vivida como neutra e científica, secularmente praticada e vitoriosa. A prática de pesquisa é uma prática política, e a adesão a teorias e formas de pesquisa é também uma adesão política.

Ao entrarmos hoje em qualquer dependência de qualquer universidade, é quase certo nos depararmos com alguém ou muitos fazendo um projeto, um plano.

Com um olhar de pássaro, poderíamos ver muitos, talvez milhares de projetos e planos sendo concebidos, pensados, detalhados... Com um olhar um pouco mais estrangeiro, talvez pensássemos ser um novo tipo de mania que tenha atacado coletivamente todo tipo de pessoas, de todas as idades... há crianças na pré-escola fazendo projetos, há adultos já envelhecidos fazendo planos... Talvez pudéssemos pensar que o presente se mostra tão horrível que, não o suportando, as pessoas tivessem sido atacadas por um desejo poético de sonhar o futuro... Mas não, os projetos e planos descrevem um futuro prático, querem ser aplicados, querem resultados, querem forçar o futuro a existir segundo seus objetivos. Talvez essa extrema banalização nas humanidades, trazida pela quantidade de apelos à produtividade, aos ganhos e à carreira e pelo ativismo inconsciente, seja o sinal da sua degradação e declínio.

Espanta a quantidade de projetos que propõem investigações e transformaçôes em locais e pessoas distantes, mas que dificilmente incluem, como reflexão, o método, as próprias pessoas e os locais onde são 
planejados, e seus papéis como agentes de política. Parece que basta ter o formato adequado, e tudo se legitima tacitamente.

Os institutos e as faculdades de educação têm sempre projetos para tudo e todos: empresas, instituiçôes e governos diversos, de vez que atualmente o mundo todo foi transformado em ambiente educacional, pronto para receber orientações pedagógicas. Espanta essa quantidade de projetos que propóem o bem a ser alcançado, a transformação de grupos e até instituições inteiras em direção à bem-aventurança.

Também a busca de conhecimento, que costuma ser uma procura complexa e incerta nas luzes e sombras da cultura das sociedades, adquiriu as feições e o espírito de projeto. $\mathrm{O}$ ato de conhecer, como também o ato de ensinar, não são mais atos, são projetos.

O pesquisador e o professor não são mais responsáveis intelectuais pelos seus atos, mas gestores e participantes de projetos com data marcada para começar e encerrar, como se seus objetos de conhecimento fossem bens de produção e consumíveis durante um determinado tempo.

Não é difícil perceber a alienação ética aí gestada. A ética, ou simplesmente a moralidade, está de fora dessa coisa objetiva e prática que é um projeto, inclusive em projetos cujo objeto é a própria ética, ou sua irmã, a cidadania, transformadas meramente em textos, entrevistas, idéias de teóricos, didatismo vulgar, propostas para um mundo melhor, que certamente não incluem o mundo pessoal e profissional do pesquisador, mas dirigem-se sempre a outras comunidades fora da universidade e, no mais das vezes, a essa comunidade virtual: "a sociedade como um todo", uma expressão vazia de sentido.

Quantos grupos não propõem a outros grupos de pessoas os objetos de seus projetos, aquilo que não exercitam entre si. Uma irresponsabilidade permitida pela ideologia da técnica de planos e projetos, sempre algo a ser aplicado ao outro, tendo em vista a melhoria do outro, que, por um mecanismo de legitimação recíproca, isenta a todos de auto-reflexão.

Não há projeto que não necessite de dinheiro para se realizar... não há projeto que não se amolde aos desígnios dos financiadores... não há projeto que não vá ser verificado pela avaliação, a moderna forma de assujeitamento e educação política.

Quantas vezes a avaliação não induz à mentira, à falsificação de resultados. Quantas vezes os pesquisadores já não fazem o projeto para 
propiciar a aprovação dos avaliadores, como em outros tempos se faziam rituais com coisas agradáveis para conquistar a boa vontade de deuses incógnitos e imprevistos.

Não é difícil percebermos que todos os projetos estão ficando muito iguais... o mesmo formato envolve todo e qualquer objeto, e da mesma forma os avaliadores institucionais já têm um modelo geral que aplicam a todo e qualquer projeto.

A separação de forma e conteúdo, tantas vezes estudada e denunciada como a operação por excelência da alienação capitalista, hoje é aceita, talvez com consciência infeliz, por todos os intelectuais que fazem projetos, empurrando-os todos à direita, como dizíamos em outro século.

No interior dos projetos, duas perguntas funcionalistas conduzem-nos. Ora propõem diagnósticos, projetos "científicos" - como é, como se dão as relaçôes etc. -; ora prognosticam, projetos "pedagógicos" - como deve ser etc. -; ora, mais completos, mais oficiais, combinam as duas perguntas.

Como então falar de ética, cidadania, educação, esses "objetos" tão gerais? Como não perceber em todos os projetos e planos a proposta abstrata de alcançar um bem? Não há projeto ou plano que não proponha um bem para o futuro. Não há projeto ou plano que não eluda o presente, matando-o, forçando-o a transformar-se em nome do "futuro bem", que somente os pesquisadores e planejadores desejam e conhecem.

No mundo da educação, de posse do conhecimento de como deve ser a "sociedade perfeita", neo-escolásticos, portadores da boa nova, criam o currículo como a projeção da "cidade ideal do bem", e as disciplinas e os projetos definem a sua prática diária, o cotidiano nessa "cidade perfeita”.

A educação aquiniana, como vimos, é uma pedagogia que, tendo como fundo verdades indemonstráveis, tem por base as disciplinas práticas e, por meio de sucessivas operações discriminatórias, dedutivas e causais, conduz o conhecimento a graus superiores de transcendência e abstrações, ao aprendizado e à interiorização dos "fundamentos", em aproximações sucessivas em direção ao "fundamento original". Mas não podemos nem afirmar que a "educação pelo currículo" em nossas instituições educativas seja uma educação escolástica, o que poderia ser até elogioso e convincente numa visão conservadora e tradicional. 
Basta que observemos a inversão que acontece quando, ao organizarem o currículo, os educadores colocam as disciplinas que chamam de fundamentos no início ou como base para todo o resto, replicando, invertidamente, a estrutura escolástica. Mas isso garante para os professores de fundamentos o de se atribuírem importância e poder. Aí sim, bem ao gosto e modelo das organizações religiosas.

É evidente que a inversão apontada é uma mistura de ignorância e política. $\mathrm{O}$ currículo tem a aparência de alguma coisa relacionada ao conhecimento, mas esconde o fato de ser uma política educacional e social de grupos externos e internos às universidades, uma pedagogia.

Currículos e projetos parecem propor, a todo instante, a "cidade ideal", a "cidade de todo bem", inalcançável, pois não é deste mundo... e devemos continuar a derrubar, reformar e construir igrejas, isto é, escolas.

Como a "cidade real" de funcionários, alunos e professores não realiza nunca a "cidade do currículo", essa cidade real é a cidade do mal, onde quase nada "dá certo", um caos organizado, e por isso deve ser avaliada constantemente, reformada constantemente, ao sabor dos "projetistas ideais da cidade do bem", da educação.

\section{Comentário de fundo}

Pasolini escreve, em 30 de novembro de 1961, no semanário do Partido Comunista Italiano Vie Nuove, n. 47:

Nada morre jamais numa vida. Tudo sobrevive. Nós, ao mesmo tempo, vivemos e sobrevivemos. Assim também toda a cultura é sempre entrelaçada de sobrevivências. No caso que estamos agora examinando, o que sobrevive são aqueles famosos 2 mil anos de imitatio Christi, aquele irracionalismo religioso. Eles não têm mais sentido, pertencem a um outro mundo, negado, recusado, superado; e, no entanto, sobrevivem. São elementos historicamente mortos mas humanamente vivos que nos compõem. Penso que seria ingênuo, superficial, faccioso negar ou ignorar sua existência. Eu, pessoalmente, sou anticlerical (não tenho nenhum medo de afirmá-lo), mas sei que em mim existem 2 mil anos de cristianismo: eu construí com meus antepassados as igrejas românicas, e depois as igrejas góticas, e depois as igrejas barrocas: elas são meu patrimônio, no conteúdo e no estilo. Seria louco se ne- 
gasse essa força poderosa que existe em mim: se deixasse para os padres (acrescento: para os educadores) o monopólio do Bem.

Recebido em agosto de 2004 e aprovado em setembro de 2004.

Referências bibliográficas

ATANÁSIO, SANTO. Contra os pagãos, a encarnação do verbo, apologia ao Imperador Constâncio, apologia de sua fuga, vida e conduta de Santo Antão. São Paulo: Paulus, 2002.

NORMAN, D. (Ed.). Siena, Florence and Padua: art, society and religion 1280-1400. New Haven; London: Yale University, 1995. v. 2.

PASOLINI, P.P. Le belle bandiere. Roma: Riunite, 1978.

TOMÁS DE AQUINO, SANTO. Sobre o ensino (De magistro) e os sete pecados capitais. São Paulo: Martins Fontes, 2002.

TOMÁS DE AQUINO, SANTO. Suma teológica. São Paulo: Loyola, 2003. 
O triunfo da escolástica, a glória da educação

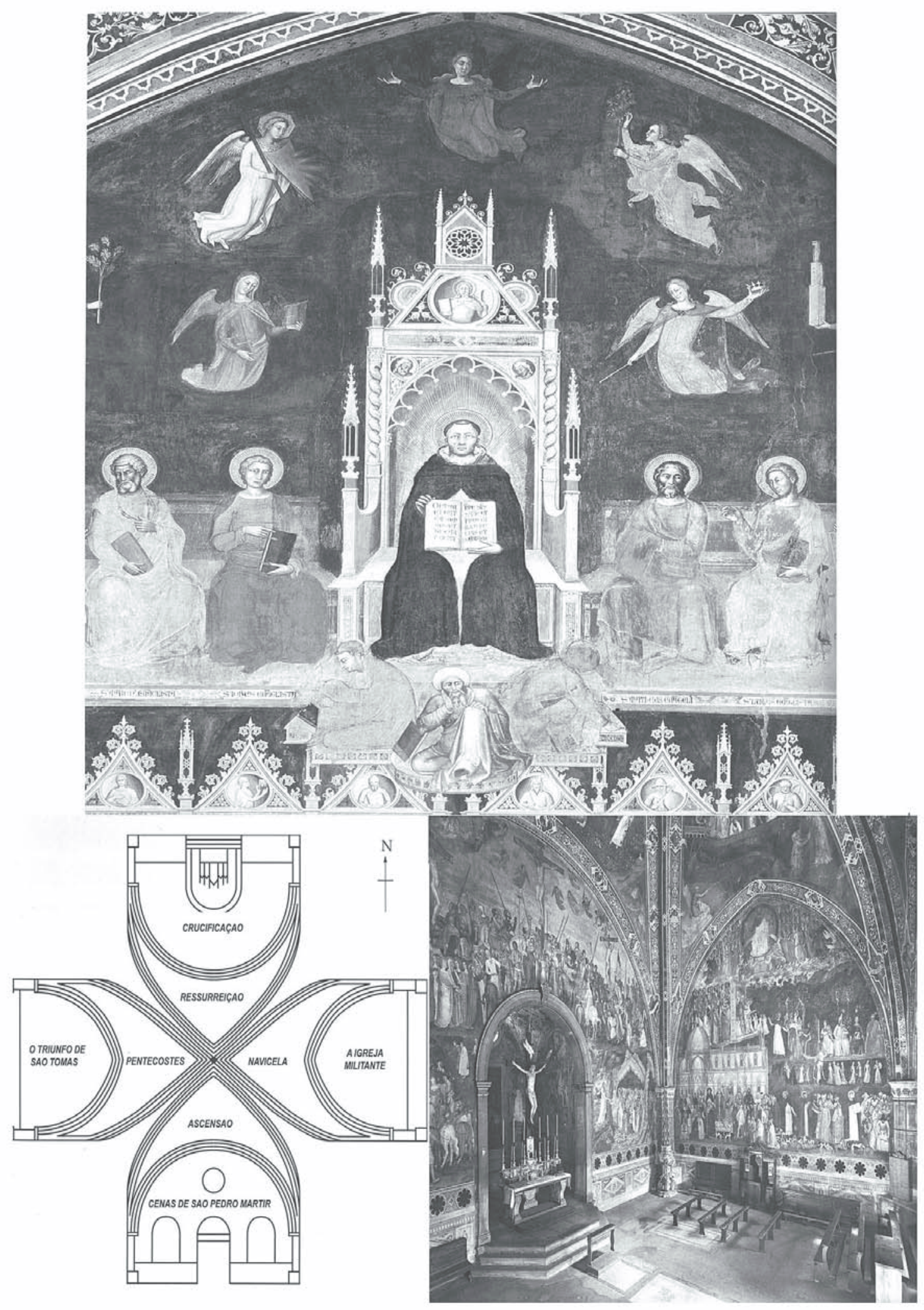

Bonaiuti, O Trïunfo de Sao Tomas, esquema e interior 


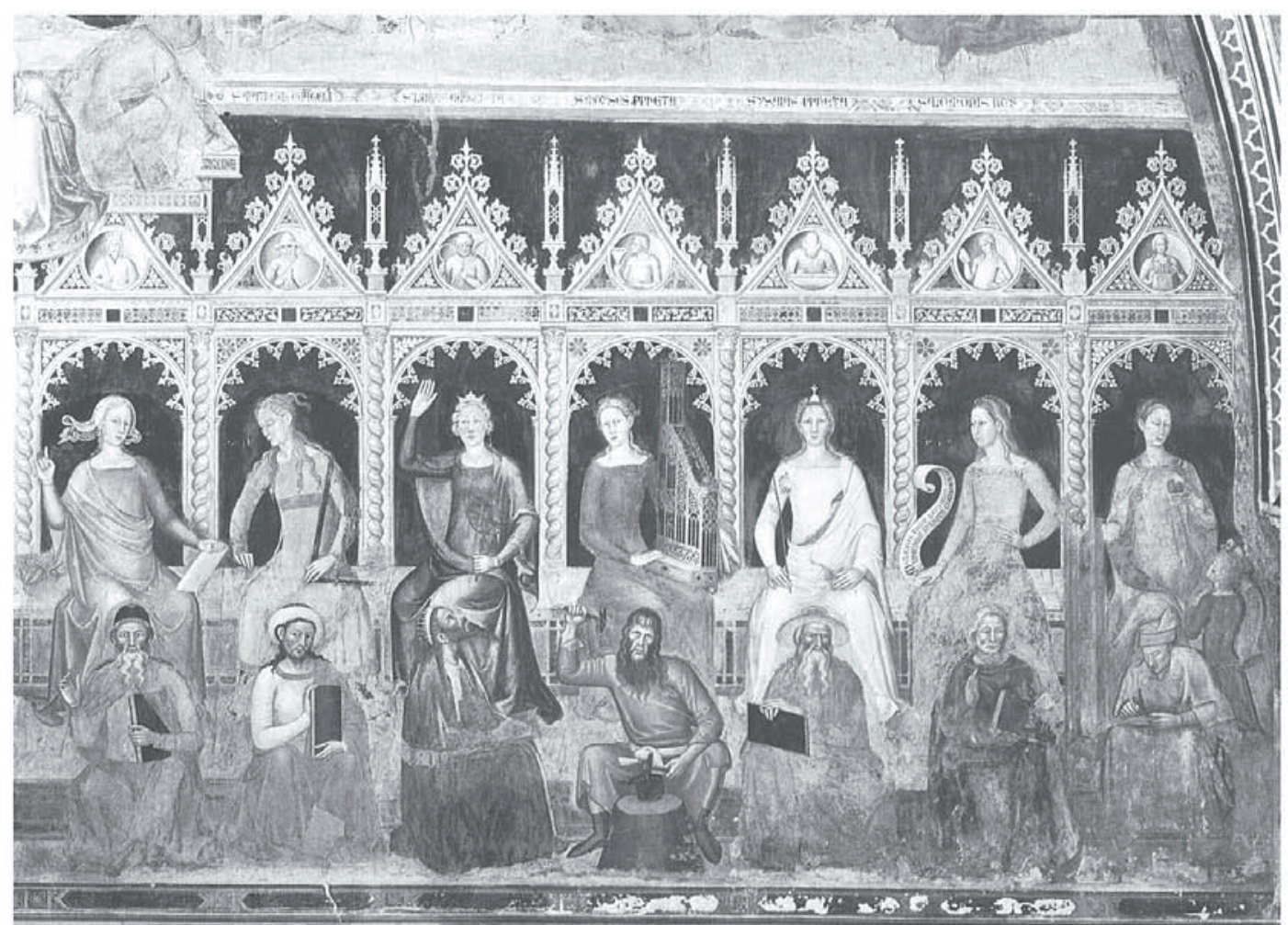

Bonaiuti, O Triunfo de Sao Tomas, As Artes Liberais

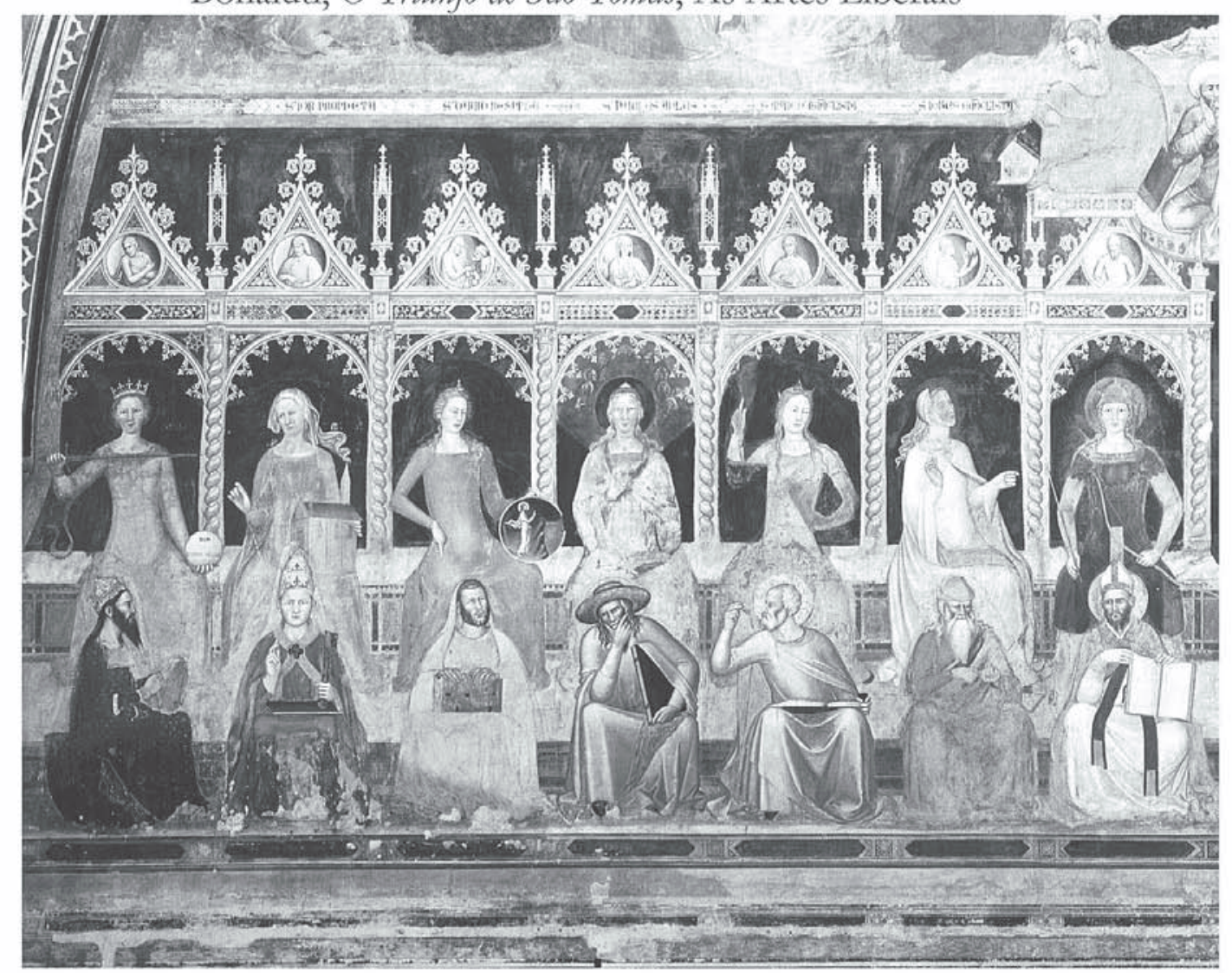

Bonaiuti, O Triunfo de Sao Tomas, As Ciencias Teologais

Educ. Soc., Campinas, vol. 26, n. 90, p. 17-39, Jan./Abr. 2005

Disponível em <http://www.cedes.unicamp.br> 
O triunfo da escolástica, a glória da educação

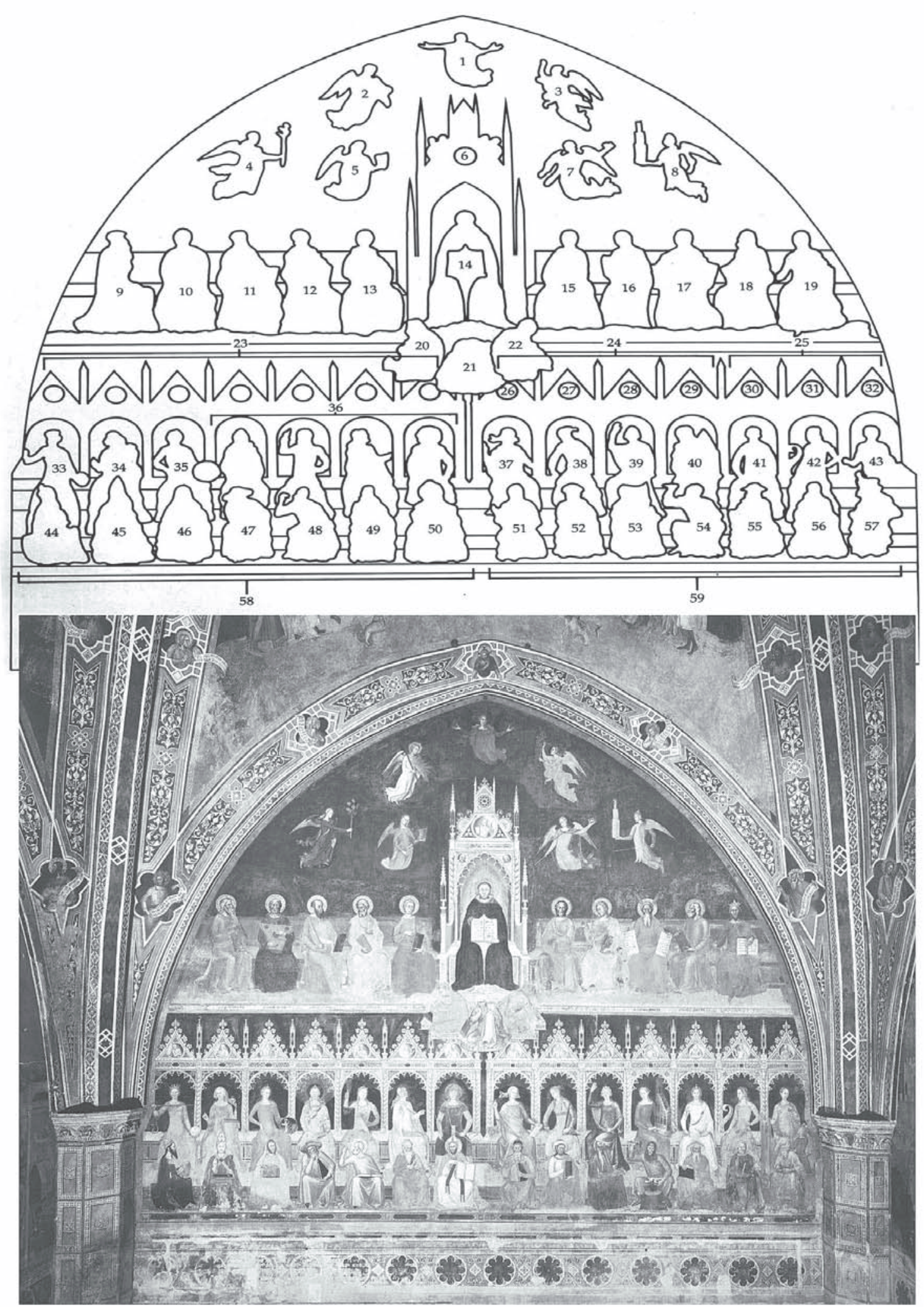

Bonaiuti, O Triunfo de Sao Tomas

Educ. Soc., Campinas, vol. 26, n. 90, p. 17-39, Jan./Abr. 2005

Disponível em <http://www.cedes.unicamp.br> 


\section{Legenda}

$\begin{array}{ll}1 \text { - Caridade } & 31 \text { - Vênus } \\ 2 \text { - Fé } & 32 \text { - Lua } \\ 3 \text { - Esperança } & 33 \text { - Direito civil } \\ 4 \text { - Temperança } & 34 \text { - Direito canônico } \\ 5 \text { - Prudência } & 35 \text { - Teologia antiga } \\ 6 \text { - Sabedoria } & 36 \text { - Quatro ciências teológicas } \\ 7 \text { - Justiça } & 37 \text { - Aritmética } \\ 8 \text { - Fortaleza } & 38 \text { - Geometria } \\ 9 \text { - Trabalho } & 39 \text { - Astronomia } \\ 10 \text { - David } & 40 \text { - Música } \\ 11 \text { - São Paulo } & 41 \text { - Dialética } \\ 12 \text { - São Marco } & 42 \text { - Retórica } \\ 13 \text { - São João Evangelista } & 43 \text { - Gramática } \\ 14 \text { - São Tomás de Aquino } & 44-\text { Justiniano } \\ 15 \text { - São Mateus } & 45 \text { - Clemente V ou Inocêncio IV } \\ 16 \text { - São Lucas } & 46 \text { - Platão } \\ 17 \text { - Moisés } & 47 \text { - São Jerônimo } \\ 18 \text { - Isaías } & 48 \text { - São Dionísio Aeropagita } \\ 19 \text { - Salomão } & 49 \text { - São João Damasceno } \\ 20 \text { - Sibélius } & 50 \text { - São Augustinho } \\ 21 \text { - Averroés } & 51 \text { - Pitágoras } \\ 22 \text { - Ário } & 52 \text { - Euclides } \\ 23 \text { - Sete dons do Espírito Santo } & 53 \text { - Ptolomeu } \\ 24 \text { - Quadrivium } & 54 \text { - Tubalcain } \\ 25 \text { - Trivium } & 55 \text { - Aristóteles } \\ 26 \text { - Sol } & 56 \text { - Cícero } \\ 27 \text { - Marte } & 57 \text { - Donato } \\ 28 \text { - Saturno } & 58 \text { - As ciências teologais } \\ 29 \text { - Júpiter } & 59 \text { - As artes liberais } \\ 30 \text { - Mercúrio } & \end{array}$

Educ. Soc., Campinas, vol. 26, n. 90, p. 17-39, Jan./Abr. 2005

Disponível em <http://www.cedes.unicamp.br> 